(C) 1984. The Genetical Society of Great Britain

\title{
CHIASMA FREQUENCY AND DISTRIBUTION IN THE PRESENCE AND ABSENCE OF SUPERNUMERARY CHROMOSOME SEGMENTS IN THE GRASSHOPPER, EUCHORTHIPPUS PULVINATUS GALLICUS
}

\author{
E. RIVA*, D. P. FOX†, R. GIRALDEZ $\ddagger$ AND J. L. SANTOS* \\ * Departmento de Genetica, Facultad de Biologia, Universidad Complutense de Madrid, \\ Spain; †Department of Genetics, University of Aberdeen, Scotland; $\ddagger$ Departmento de \\ Genetica, Universidad de Oviedo, Spain.
}

Received 6.xii.83

\section{SUMMARY}

\begin{abstract}
The presence of a heterochromatic, supernumerary segment (one or two doses) near the centromeric end of chromosome $\mathbf{S} 8$ in the grasshopper Euchorthippus pulvinatus gallicus leads to the bivalents at diplotene of male meiosis having a significantly raised chiasma frequency. Bivalent length is also increased but cannot account for the increased chiasma frequency through the "length effect". The supernumerary segment may influence chiasma position in the S8 bivalent but does not appear to influence chiasma position in other bivalents which normally only carry a single chiasma. There is little evidence for interference operating across the centromere in metacentric chromosomes.
\end{abstract}

\section{INTRODUCTION}

Euchorthippus pulvinatus gallicus is a grasshopper with $2 n=17\left({ }^{\star}\right) 18(\%)$ consisting of three pairs of metacentric autosomes, five pairs of telocentric autosomes and a telocentric $X$. It is widely distributed in the Iberian Peninsula. Several polymorphisms are present for supernumerary C-band material including a particularly marked polymorphism for a proximal band in the $\mathbf{S} 8$ chromosome, which can be readily recognised in male meiotic cells (Santos and Giraldez, 1982).

It has been shown in many organisms (grasshoppers-Henderson, 1963; Southern, 1967; Fox, 1973; tulips-Couzin and Fox, 1974; Man-Laurie, 1980) that chiasma frequency varies between cells within individuals and that this variation shows a positive correlation with total autosomal length. In Schistocerca gregaria Fox (1973) concluded that this "length effect" operates at the level of the cell and not the individual bivalent since:

(i) the length of the univalent, achiasmate $X$ is positively correlated with cell chiasma frequency

(ii) the length of a bivalent which only forms a single chiasma is positively correlated with cell chiasma frequency

(iii) for cells which have the same chiasma score there is no correlation between individual bivalent length and bivalent chiasma score.

The presence of supernumerary heterochromatic material, whether as $B$-chromosomes or supernumerary segments, often leads to changes in chasma frequency and/or position (see John, 1973 for example). Most commonly chiasma frequency is increased by the presence of supernumerary chromosome segments but with the main effect being produced by the 
addition of one segment and little evidence of additivity in the SS homozygote. In this paper we examine the influence of the S8 supernumerary segment of Euchorthippus pulvinatus gallicus upon chiasma position and chiasma frequency. We also examine the hypothesis that the clear increase in chiasma frequency brought about by the presence of this segment operates through the length effect.

\section{Materials AND Methods}

Males of Euchorthippus pulvinatus gallicus were collected from Desviacion de Mauzanares (Madrid) in September 1979. Testes were dissected and fixed in acetic alcohol prior to squashing in 45 per cent acetic acid, followed by the C-banding technique described by Santos and Giraldez (1978).

Photographs were taken of 9-12 C-banded diplotenes from 10 animals of each genotype BB (homozygous for absence of segments), BS (heterozygous), SS (homozygous for presence of segments). There was some variation in C-band size but this was not quantified. Bivalent lengths and chiasma positions were recorded in arbitrary units by using a small gear wheel to follow the bivalent in such a way that it left an imprint of the teeth on the photographic paper. The number of units of arbitrary length could then be counted for each chromosome segment defined by the chromosome ends and chiasma positions. These were defined by Mather's (1937) notation of $D, I$ and $R$ distances. Individual chromosomes and chromosome arms may be recognised in this species following C-banding (Santos and Giraldez, 1982).

\section{Results AND Discussion}

Plates $a-c$ show typical C-banded diplotenes of the three karyotypes. Mean total bivalent length and mean chiasma score are recorded in table 1 for each individual of each karyotype. An analysis of variance shows that the $B S$ and $S S$ karyotypes have significantly higher mean chiasma scores than the $B B$ karyotype (V.R. 2, $27=6 \cdot 15, p=0 \cdot 01-0 \cdot 001$ ) though $B S$ and $S S$ are not significantly different from each other. In parallel with the chiasma scores, the mean autosomal length is greater in BS (376.82 A.U.) and SS (383.83 A.U.) than in $B B(337.67$ A.U.) although the difference between genotypes is not significant (V.R. $(2,27)=2 \cdot 07, p=0 \cdot 2-0 \cdot 1)$. This latter result is not unexpected since the degree of contraction of the chromosomes increases considerably during the course of diplotene giving a high variance for this parameter. The polymorphic segment on the S8 chromosome of Euchorthippus pulvinatus gallicus is thus very similar in its effect on chiasma frequency to similar segments on M7 and S8 of Chorthippus parallelus (John and Hewitt, 1969) and the three smaller autosomes of Phaulacridium marginale (Westerman, 1977). The parallel between the effect of the supernumerary segment on the mean cell chiasma score $(B B<B S=S S)$ and the mean total bivalent length (table 1) appears to support the length effect as a possible mechanism for the action of the supernumerary segment.

A joint regression analysis of cell chiasma score on total autosome length showed that, while there is no significant difference in the regression slopes between individuals (V.R. $(29,256=1 \cdot 58, p=0 \cdot 1-0 \cdot 05)$, there is a highly 


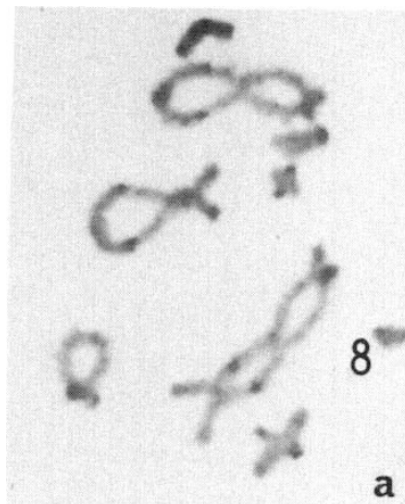

a

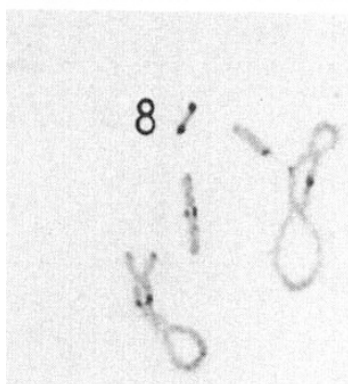

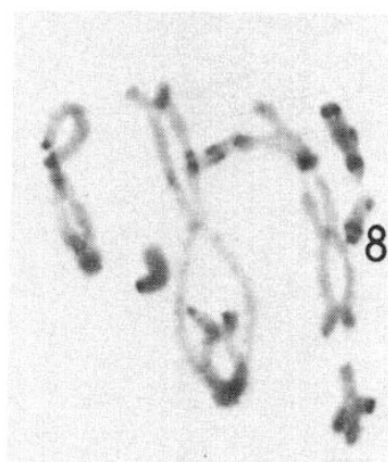

b
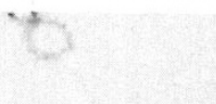

\section{8}

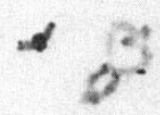

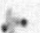

C

Plate. C-banded diplotenes from karyotypes $B B$ (a), $B S$ (b) and $S S$ (c). Magnifications (a) $\times 1100$, (b) $\times 1600$, (c) $\times 720$. 
TABLE 1

Mean chiasma score ( \pm S.E.) and mean total autosome length (arbitrary units $\pm S . E$.) for the ten individuals of each karyotype

\begin{tabular}{cccc}
\hline \multirow{2}{*}{ Karyotype } & Individual & $\begin{array}{c}\text { Chiasma } \\
\text { mean } \pm \text { S.E. }\end{array}$ & $\begin{array}{c}\text { Length } \\
\text { mean } \pm \text { S.E. }\end{array}$ \\
\hline \multirow{3}{*}{$B B$} & 1 & $13 \cdot 3 \pm 0 \cdot 4$ & $287 \cdot 5 \pm 35 \cdot 4$ \\
& 2 & $14 \cdot 3 \pm 0 \cdot 3$ & $338 \cdot 9 \pm 17 \cdot 7$ \\
& 3 & $13 \cdot 0 \pm 0 \cdot 2$ & $397 \cdot 2 \pm 23 \cdot 1$ \\
& 4 & $14 \cdot 4 \pm 0 \cdot 3$ & $362 \cdot 5 \pm 14 \cdot 0$ \\
& 5 & $14 \cdot 6 \pm 0 \cdot 3$ & $350 \cdot 8 \pm 15 \cdot 7$ \\
& 6 & $12 \cdot 7 \pm 0 \cdot 3$ & $329 \cdot 6 \pm 22 \cdot 8$ \\
& 7 & $13 \cdot 3 \pm 0 \cdot 3$ & $380 \cdot 1 \pm 23 \cdot 7$ \\
& 8 & $13 \cdot 0 \pm 0 \cdot 2$ & $325 \cdot 8 \pm 5 \cdot 4$ \\
$B S$ & 9 & $13 \cdot 4 \pm 0 \cdot 3$ & $340 \cdot 4 \pm 11 \cdot 1$ \\
& 10 & $12 \cdot 8 \pm 0 \cdot 3$ & $291 \cdot 5 \pm 10 \cdot 5$ \\
& 1 & $14 \cdot 4 \pm 0 \cdot 5$ & $423 \cdot 4 \pm 32 \cdot 3$ \\
& 2 & $13 \cdot 3 \pm 0 \cdot 1$ & $425 \cdot 0 \pm 24 \cdot 0$ \\
& 3 & $14 \cdot 2 \pm 0 \cdot 4$ & $376 \cdot 0 \pm 17 \cdot 3$ \\
& 4 & $13 \cdot 8 \pm 0 \cdot 4$ & $340 \cdot 1 \pm 15 \cdot 9$ \\
& 5 & $14 \cdot 5 \pm 0 \cdot 2$ & $450 \cdot 8 \pm 13 \cdot 7$ \\
& 6 & $15 \cdot 6 \pm 0 \cdot 3$ & $422 \cdot 3 \pm 19 \cdot 7$ \\
& 7 & $15 \cdot 0 \pm 0 \cdot 4$ & $401 \cdot 0 \pm 19 \cdot 3$ \\
& 8 & $14 \cdot 1 \pm 0 \cdot 3$ & $344 \cdot 8 \pm 18 \cdot 8$ \\
& 9 & $13 \cdot 9 \pm 0 \cdot 3$ & $337 \cdot 1 \pm 17 \cdot 7$ \\
& 10 & $14 \cdot 4 \pm 0 \cdot 3$ & $296 \cdot 1 \pm 12 \cdot 3$ \\
& 1 & $15 \cdot 9 \pm 0 \cdot 5$ & $468 \cdot 4 \pm 14 \cdot 5$ \\
& 2 & $14 \cdot 7 \pm 0 \cdot 4$ & $330 \cdot 6 \pm 12 \cdot 0$ \\
& 3 & $14 \cdot 9 \pm 0 \cdot 4$ & $412 \cdot 4 \pm 16 \cdot 0$ \\
& 4 & $13 \cdot 6 \pm 0 \cdot 3$ & $382 \cdot 6 \pm 29 \cdot 9$ \\
& 5 & $15 \cdot 0 \pm 0 \cdot 2$ & $380 \cdot 1 \pm 11 \cdot 2$ \\
& 6 & $13 \cdot 6 \pm 0 \cdot 3$ & $324 \cdot 9 \pm 15 \cdot 9$ \\
& 7 & $15 \cdot 0 \pm 0 \cdot 3$ & $472 \cdot 4 \pm 22 \cdot 1$ \\
& 8 & $14 \cdot 3 \pm 0 \cdot 3$ & $386 \cdot 1 \pm 16 \cdot 4$ \\
& 9 & $14 \cdot 6 \pm 0 \cdot 2$ & $252 \cdot 3 \pm 4 \cdot 9$ \\
& 10 & $13 \cdot 9 \pm 0 \cdot 4$ & $379 \cdot 3 \pm 15 \cdot 7$ \\
\hline
\end{tabular}

significant difference between adjusted means (V.R. $(29,285=4 \cdot 57, p<$ 0.001 ) and thus no justification for pooling data from different individuals of the same karyotype. However, since the regression slopes do not differ significantly between individuals, it is possible to use the slope of the common regression $\left(b=3.9 \times 10^{-3}\right)$ to adjust the individual cell chiasma scores to the mean autosome length for all individuals ( $365 \cdot 52 \mathrm{~A}$.U.). This procedure removes the variation in chiasma score due to the length effect and so, if this effect is responsible for much or all of the increase in chiasma score in $B S$ and $S S$ karyotypes over the $B B$ karyotype, then an analysis of variance of the adjusted chiasma scores should show a reduced level or no significant difference between karyotypes. This prediction is not fulfilled since a highly significant difference remains between the karyotypes (V.R. $(2,27)=5 \cdot 13$, $p \sim 0.01)$ though $B S$ and $S S$ are again not significantly different (V.R. $(18,1)=1 \cdot 42, p<0 \cdot 2)$. Since chromosome arms L2S, L3S and chromosomes M5, M6, M7 and S8 rarely form more than one chiasma in any cell of any karyotype, this analysis was repeated using only data from chromosome $\mathrm{Ll}$, which shows chiasma frequency variation in both arms. However, the results 
of this analysis are very similar to the analysis of total cell chiasma frequency. When Ll chiasma scores, adjusted to mean Ll length using the slope of the joint regression, are subjected to the analysis of variance a highly significant difference between the karyotypes remains (V.R. $(2,27)=6 \cdot 757$, $p=0.01-0.001)$. The minimal effect of the adjustment procedure can be seen by comparing the true mean and the adjusted mean cell chiasma scores and Ll chiasma scores for the three karyotypes (table 2). The clear conclusion

TABLE 2

True and adjusted mean cell chiasma scores for the three karyotypes

\begin{tabular}{ccccc}
\hline & \multicolumn{4}{c}{ Chiasma frequency } \\
\cline { 2 - 5 } & \multicolumn{2}{c}{ True mean } & \multicolumn{2}{c}{ Adjusted mean } \\
\cline { 2 - 5 } Karyotype & Total cell & L1 & Total cell & Ll \\
\hline BB & 13.50 & $2 \cdot 90$ & $13 \cdot 60$ & $2 \cdot 92$ \\
BS & $14 \cdot 32$ & 3.30 & $14 \cdot 27$ & 3.28 \\
SS & 14.56 & 3.22 & 14.51 & 3.21 \\
\hline
\end{tabular}

to be drawn is that, while the supernumerary segment may slightly increase the total autosome length at diplotene, this is not responsible for the bulk of the increase in cell chiasma frequency. However, it must be remembered that these animals are collected from a wild population and so interactions between the segments and a variable background genotype, which cannot be detected with this experimental design, may well be important in determining chiasma frequency. A much more precise test would be to measure the effect of the presence of 0,1 or 2 copies of the segment in a uniform genetic background.

There is some evidence that supernumerary chromosomes and chromosome segments may influence chiasma position as well as chiasma frequency both in the karyotype generally and in the chromosomes carrying the supernumerary segments (Jones and Rees, 1967; Santos and Giraldez, 1982). Testing for this possibility is complicated in bivalents having more than one chiasma by the operation of interference. No such problem arises with chromosomes M5, M6, M7, S8 and the short arms of $L_{2}$ and $L_{3}$ in Euchorthippus pulvinatus gallicus since they rarely form more than one chiasma. Each chromosome (or chromosome arm) under test was divided into 10 equal segments and the frequency of chiasma formation in the 10 segments compared between the karyotypes using a contingency $\chi^{2}$. The results are contained in table 3. Two results (M6 and S8) exceed the 5 per cent probability level and these distributions have been examined in more detail.

In M6 karyotypes $B S$ and $S S$ do not differ for chiasma distribution. $B B$ differs from them in having a higher proportion of chiasmata at the telomere and a lower proportion in the proximal 30 per cent of chromosome length. S8 differs from M6 in that karyotypes $B B$ and $S S$ do not differ and $B S$ had a dearth of chiasmata in the proximal 40 per cent of the chromosome length, i.e., adjacent to the locus of the heterozygous $C$-band. The first point to note is that M6 and S8 are the only chromosomes which commonly carry polymorphic C-bands (Santos and Giraldez, 1982). M7 rarely has a supernumerary segment which was not present in our sample. In the case of S8 it 
TABLE 3

Chiasma distribution within those bivalents and arms (L2S, L3S, MS, M6, M7, S8) which normally form only one chiasma. Each segment represents 10 per cent of the mean bivalent or arm length with 1 being adjacent to the telomere and 10 adjacent to the centromere

\begin{tabular}{|c|c|c|c|c|c|c|c|c|c|c|c|}
\hline \multirow{2}{*}{$\begin{array}{l}\text { Chromosome } \\
\text { or arm }\end{array}$} & \multirow[b]{2}{*}{ Karyotype } & \multicolumn{10}{|c|}{ Segment } \\
\hline & & 1 & 2 & 3 & 4 & 5 & 6 & 7 & 8 & 9 & 10 \\
\hline \multirow[t]{3}{*}{ L2S } & $B B$ & 42 & 42 & 13 & 6 & 0 & 0 & 0 & 0 & 0 & 0 \\
\hline & $B S$ & 48 & 41 & 11 & 0 & 0 & 0 & 0 & 0 & 0 & 0 \\
\hline & $S S$ & 44 & 37 & 13 & 0 & 0 & 0 & 0 & 0 & 0 & 0 \\
\hline \multirow[t]{3}{*}{ L3S } & $B B$ & 54 & 39 & 10 & 1 & 0 & 0 & 0 & 0 & 0 & 0 \\
\hline & $B S$ & 56 & 37 & 7 & 1 & 0 & 0 & 0 & 0 & 0 & 0 \\
\hline & SS & 62 & 33 & 7 & 0 & 0 & 0 & 0 & 0 & 0 & 0 \\
\hline \multirow[t]{3}{*}{ M5 } & $B B$ & 30 & 2 & 8 & 7 & 14 & 13 & 12 & 7 & 5 & 0 \\
\hline & $B S$ & 39 & 2 & 2 & 8 & 7 & 7 & 13 & 9 & 4 & 3 \\
\hline & $S S$ & 43 & 3 & 2 & 10 & 7 & 11 & 6 & 6 & 0 & 1 \\
\hline \multirow{3}{*}{ M6 } & $B B$ & 36 & 0 & 2 & 14 & 19 & 9 & 12 & 5 & 7 & 1 \\
\hline & $B S$ & 21 & 0 & 4 & 13 & 10 & 13 & 14 & 11 & 14 & 3 \\
\hline & $S S$ & 27 & 0 & 3 & 8 & 12 & 13 & 14 & 18 & 8 & 1 \\
\hline \multirow[t]{3}{*}{ M7 } & $B B$ & 63 & 1 & 0 & 4 & 10 & 8 & 9 & 4 & 6 & 0 \\
\hline & $B S$ & 60 & 0 & 2 & 2 & 5 & 6 & 8 & 16 & 6 & 1 \\
\hline & $S S$ & 55 & 0 & 1 & 4 & 5 & 12 & 13 & 12 & 2 & 0 \\
\hline \multirow[t]{3}{*}{ S8 } & $B B$ & 67 & 0 & 2 & 1 & 8 & 11 & 9 & 3 & 4 & 0 \\
\hline & $B S$ & 74 & 0 & 1 & 5 & 10 & 12 & 3 & 1 & 0 & 0 \\
\hline & $S S$ & 66 & 0 & 3 & 8 & 10 & 6 & 9 & 2 & 1 & 0 \\
\hline
\end{tabular}

is possible that the $\mathrm{C}$-band has a direct influence on chiasma formation in its immediate vicinity. It could also be having an indirect effect on M6 but a more likely explanation is a local effect due to the M6 polymorphic C-bands which, unlike the band on S8, cannot be readily distinguished at meiosis. The presence or absence of the S8 band certainly does not seem to influence chiasma position in the structurally constant chromosomes and arms tested.

There is no doubt that interference is an important mechanism restricting chiasma distribution within telocentrics and the separate arms of metacentrics but there is uncertainty about the operation of this mechanism between chromosome arms across the centromere. Southern (1967) tested this hypothesis by looking for correlations between arm chiasma frequencies for the metacentric chromosomes of four grasshopper species. Of 15 correlations 7 were positive (one significant) and eight negative (none significant). Laurie (1980) used percentage D-distances in a similar analysis for the $\mathrm{L}_{3}$ chromosome in Chorthippus brunneus ot diplotene and found 10 out of 93 correlations to be negative and significant. We have used a similar test to Laurie, looking for correlations between D-distances of long and short arms of the three pairs of metacentric chromosomes. The D-distances were first adjusted to the mean bivalent length in order to remove the effects of differential contraction. The results are summarised in table 4 . By using adjusted D-distances we confine the test to the area of the bivalent over which inter-arm interference must operate, if it exists. The data in table 4 indicates that interference does not in general operate across the centromere. 
TABLE 4

Correlation coefficients for transformed D-distances in the three metacentric chromosomes $\{D($ long arm) vs. $D($ short $a r m)$ for the three karytopes, $P=$ probability, $r=$ correlation coefficient

\begin{tabular}{|c|c|c|c|c|c|c|}
\hline \multirow[b]{3}{*}{ Karyotype } & \multicolumn{6}{|c|}{ Bivalent } \\
\hline & \multicolumn{2}{|c|}{$\mathrm{Ll}$} & \multicolumn{2}{|c|}{ L2 } & \multicolumn{2}{|c|}{ L3 } \\
\hline & $r$ & $p$ & $r$ & $p$ & $r$ & $p$ \\
\hline$B B$ & -0.224 & $0.05-0.02$ & -0.183 & $0.1-0.05$ & +0.011 & $>0.1$ \\
\hline$B S$ & -0.296 & $0.01-0.001$ & -0.184 & $0.1-0.05$ & +0.021 & $>0.1$ \\
\hline SS & +0.089 & $>0.1$ & +0.128 & $>0.1$ & -0.097 & $>0.1$ \\
\hline
\end{tabular}

However, the occurrence of two significant negative correlations for the $\mathrm{L}_{1}$ bivalent in karyotypes $B B$ and $B S$ and two further near significant negative correlations do indicate that a chiasma in one arm of a metacentric may influence the position of chiasma formation in the other arm in some circumstances.

Acknowledgements. This work was supported by grants from the Nuffield Foundation and the Comisión Asesora de Investigación Científica y Tecníca de España.

\section{REFERENCES}

COUZIN, D. A. AND FOX, D. P. 1974. Variation in chiasma frequency during tulip anther development. Chromosoma, 46, 173-179.

FOX, D. P. 1973. The control of chiasma distribution in the locust Schistocerca gregaria (Forskal). Chromosoma, 43, 289-328.

HENDERSON, S. A. 1963. Chiasma distribution at diplotene in a locust (Schistocerca gregaria). Heredity, 18, 173-190.

JOHN, B. 1973. The cytogenetic systems of grasshoppers. II. The origin and evolution of supernumerary segments. Chromosoma, 44, 123-146.

JOHN, B. AND HEWITT, G. M. 1969. Parallel polymorphism for supernumerary segments in Chorthippus parallelus (Zetterstedt). III. The Ashurst Population. Chromosoma, 28, 73-84. JONES, R. N. AND REES, H. 1967. Genotypic control of chromosome behaviour in rye. XI. The influence of $B$-chromosome on meiosis. Heredity, 22, 333-347.

LAURIE, D. 1980. Ph.D. Thesis, University of Birmingham.

MATHER, K. 1937. The determination of the position of crossing over. II. The chromosome length chiasma frequency relation. Cytologia Fujii Jub vol. pp. 514-526.

SANTOS, J. L. AND GIRALDEZ, R. 1978. The effect of C-heterochromatin in chiasma terminalisation in Chorthippus biguttulus L. (Acrididae, Orthoptera). Chromosoma, 70, 59-66.

SANTOS, J. L. AND GIRALDEZ, R. 1982. C-heterochromatin polymorphism and variation in chiasma localization in Euchorthippus pulvinatus gallicus (Acrididae, Orthoptera). Chromosoma, 85, 507-518.

SOUTHERN, D. I. 1967. Chiasma distribution in Truxalline grasshoppers. Chromosoma, 22, 164-191.

WeSteRman, M. 1977. Population cytology of the genus Phanulacridium. V. marginale-the Omara population. Aust. J. Biol. Sci., 30, 319-328. 